\title{
EU E AS FRONTEIRAS DO OUTRO
}

Cléria Botêlho da Costa*

4 ste texto apresenta alguns resultados da pesquisa intitulada Vozes da Terra - a qual se constitui num estudo de caso do assentamento de Indaiá, localizado ao sul do Mato Grosso do Sul - e tem por objetivo fazer uma análise das representações acerca da identidade e etnia dos trabalhadores rurais que lá vivem. $\mathrm{O}$ assentamento de Indaiá é um agrupamento de trabalhadores rurais oriundos de diferentes regiões do país e que têm como traço comum, a vivência no Paraguai e por isso, comumente, são conhecidos como "brasiguaios". O fio condutor da pesquisa foi a oralidade, através da qual as histórias de vida foram trabalhadas.

\section{As diferenças: 0 reconhecimento da alteridade}

O senhor Gonçalo Basílio dos Santos, um lavrador de Indaiá, mostrou sua percepção sobre algumas diferenças existentes no assentamento:

"...Aqui nós temos dois grupos: um que trabalha e o outro que vive do trabalho dos outros. Os que não trabalha é um bando de vagabundo e que só quer sugar do que nós trabalha, que quer viver às nossas custas, é a lumpaiada, e os que trabalha é quem sustenta $o$ assentamento..."

$\mathrm{O}$ relato apresentado reconhece que o assentamento não é um agrupamento homogêneo. Ali existem muitas diferenças, que são tão fortes, a ponto de se autoclassificarem como "aqueles que trabalham" e "aqueles que não trabalham", sendo os últimos denominados "lumpaiada"1 pelos primeiros.

A "lumpaiada" é percebida pelo outro subgrupo como individualista porque não aderiu ao trabalho em conjunto e frequentemente, éapontada como responsável pela desunião do grupo : "eles nem sabe o que étrabalhar engrupado...", expressou Gonçalo. O grupo que trabalha é concebido pelo outro como um conjunto de pessoas que "querem mandar no assentamento" $\mathrm{e}$ é politicamente muito rigido ou, ainda, "que não aceita fazer acordo" como disse
Neri. É exatamente a partir dessa lógica de se reconhecerem como parte de um subgrupo e captarem a diferença do outro subgrupo em relação a eles que se consolida a identidade do grupo. É nesse jogo dialético entre a semelhança e a diferença que vai se construindo a identidade coletiva deles (Brandão: 1986). Em outros termos, a partir do momento em que os lavradores de Indaiá se reconhecem pertencendo a um dos subgrupos, admitem as diferenças existentes entre eles. Estas se expressam quando uns aceitam trabalhar em conjunto e outros não, quando alguns são politicamente mais rígidos e outros mais flexíveis; a partir de então, tomam consciência da alteridade, da existência do eu e do outro.

Ainda sobre as diferentes percepções do trabalho existente no assentamento, o senhor Neri Silva, outro trabalhador de Indaiá, narrou suas experiências com muita determinação:

"...Eu quero fazer àminha roça sozinho, para trabalhar com meus filhos. Essa coisa junta acho que nunca presta. Eu quero fazer a minha só porque o dia que quiser eu vou, o dia que eu quiser tirar minha espiga de milho eu tiro, não tem de dizer não vai tirar que não é teu. Mode isso, eu vou fazer minha roça só..."

Nesse relato, Neri Silva expressou uma representação da prática do trabalho individual e das diferenças existentes no assentamento. Na concepção desses homens, está em jogo, na proposta do trabalho em conjunto, o compromisso e a obrigação como opostos à sua compreensão de liberdade e ajuda mútua. As diferenças existentes no grupo são percebidas como artimanhas do trabalho "engrupado", que lhes impõe a falta de liberdade e faz crescer as exigências políticas dos trabalhadores durante as negociações, seja em nível de Governo Federal ou Estadual.

Há uma outra dimensão do trabalho individual que eles levam em conta, que é estar intrinsecamente vinculado a casa è̀ família. Dessa maneira, o compromisso com o trabalho em conjunto pode transporse às obrigações do homem enquanto chefe de família, posição chave no seu universo.
No imaginário desses trabalhadores, a representação que fazem da liberdade está relacionada ao fato de poderem dispor de um pedaço de chão para "tocar'; de não contar com horário afixado para iniciar e terminar o trabalho na roça; não ter um patrão; poder colher os produtos que cultivam em suas roças no momento que desejarem, sendo desnecessário prestar satisfação a outrem ou, ainda, poderem dispor de um trabalho remunerado capaz de satisfazer as necessidades de suas famílias. Nesse sentido, a prática do trabalho individual é o melhor caminho para a conquista dessa independência.

A liberdade para eles se confunde com os direitos de todo cidadão. Contudo, se tais direitos podem parecer insignificantes para alguns homens, para aqueles lavradores representam uma forte proteção diante da vulnerabilidade de quem era nômade e quase sempre deixava nas mãos dos proprietários os benefícios integrais do seu trabalho. (William: 1989).

No entanto, não entendo que a independência desses trabalhadores se realize apenas com a aquisição de um pedaço de terra ou escolhendo os produtos que pretendem cultivar. É preciso ir além. É preciso que sua luta cotidiana seja ampliada; extrapole o campo e conquiste espaço nas cidades e, junto às instituições democráticas representativas da sociedade, os faça questionar e romper o monopólio da propriedade da terra (Martins: 1989). Em outros termos, a conquista da liberdade é uma tarefa eminentemente política.

Esses depoimentos também revelaram que os trabalhadores rurais que, hoje, 1993, vivem em Indaiá adotaram como critério básico para definição de sua identidade social "estar em cima da terra" que "ocuparam' '. Desde então deixaram para trás a identidade de trabalhadores rurais sem terra e tornaram-se trabalhadores que já dispunham dela para o cultivo, embora ainda não contassem com a propriedade jurídica da mesma. Sobre esta questão o Sr. Luís relatou: " "...hoje, nós já estamos em cima da terra, não somos mais sem terra...", expressando o que muitos outros 
lavradores pensavam. Contudo, vale ressaltar que essa categoria classificatória da identidade social deles (" assentados") foilhes atribuída pelo Estado para quem assentados eram todos aqueles que recebiam lotes nas áreas desapropriadas. Trata-se, portanto, de uma categoria administrativa apropriada e usada por eles como identidade básica mais geral.

Outros lavradores, no entanto, reconhecem o trabalho em grupo como a única forma de sobrevivência no assentamento e de conquistarem a independência como expressou Valdi:

"...Se nós num trabalhar engrupado nós num fica em cima dessa terra e nem vai conquistar nossa liberdade..."

Esses homens reconheciam que era necessário produzir, produzir muito naquele chão a fim de que o Instituto Nacional de Reforma Agrária (INCRA) lhes concedesse o título de proprietários da terra, não mais os expulsasse daquele chão duramente conquistado e prenhe de muitas utopias. Assim, esses trabalhadores rurais iam, no seu cotidiano, reconstruindo suas identidades de homens da roça, muitas vezes, dilaceradas pelas vivências em múltiplos espaços. Desse modo, esses homens simples, nos passos de cada dia, iam elaborando suas identidades num contínuo fazer-se. (Thompson: 1987).

Para esse grupo de homens, o trabalho em conjunto seconstitui nobode expiatório da condição estrutural de dominados em que vivem. Imagem que, certamente, foi construída a partir das experiências globais de transformações, sob a égide do Estado, vivenciadas por alguns países do mundo. Nesses países, a propriedade privada e a luta entre desiguais constituem-se pressupostos fundamentais e o trabalho coletivizado é a única realidade.

\section{Nordestinos e sulistas: "é difícil juntar os pensamentos"}

O Senhor Lídio Sampaio expressou com determinação sua percepção sobre as dificuldades de convivência entre sulistas e nordestinos em Indaiá:

“...Esse negócio de cada um de nós vir de um lugar diferente é muito complicado. Nós, os sulistas, já temos mais conhecimento de trabalhar a terra com máquinas por causa de nossa descendência dos europeus. Eu mesmo sou filho de italiano, outro é de alemão e os nordestinos coitado, só sabe mesmo abrir a cova..."

O Sr. Antonio Silva, um nordestino, também expressou sua representação sobre os sulistas:

"...Os sulistas querem mandar em nós e acham que só eles sabem trabalhar de roça..."

As falas dos senhores Lídio e Antonio apontam a clivagem étnica entre aqueles homens simples de Indaiá. Nas representações imaginárias dos sulistas estes são, supostamente, mais preparados para o trabalho da lavoura e os nordestinos percebidos como menos qualificados para o trabalho com a terra. Já para os nordestinos, aqueles são apreendidos como mandões e eficientes no trabalho da lavoura. Isso denota que, no contexto desse assentamento, existem diversas identidades étnicas em jogo: os sulistas, cuja origem dos seus ascendentes não está circunscrita à origem nacional - alemães, italianos, polacos -, e os nordestinos de origens circunscritas ao mundo rural brasileiro.

O principal argumento para não considerar os nordestinos como iguais diz respeito à terra: para os sulistas, os nordestinos não sabem e nem querem "cuidar da terra" e tampouco gostam do trabalho, portanto, afirmou Luís, "não servem" para o ofício de lavrador. A maneira como concebem a sua identidade social e étnica não passa pelas características básicas da sua condição de lavradores, quase proprietários rurais, mas por sua condição de descendentes de imigrantes, diferentes de uma outra categoria definida como nordestinos. Enquanto que o nordestino, com sua vivência em múltiplos espaços, também se percebe como diferente dos sulistas e afirma a capacidade que dispõe de lidar com a terra: "a gente sempre trabalhou na terra, mesmo que essa fosse de patrão", afirmou o Sr. Pedro Costa. Nesse sentido, a construção de sua identidade não passa, necessariamente, pelas características étnicas, mas por sua condição de lavradores.

O senhor Luís Sampaio rememorou as dificuldades do trabalhoem conjuntoe apontou algumas dificuldades na convivência entre sulistas e nordestinos:

"...Nós precisa de terra nossa porque esse negócio de terra arrendada num dá... Mas terra só não chega. Porque a terra mal cuidada nãotem produção. E também aqui tem gente de todo Estado do Brasil, com hábitos culturais diferentes. Porexemplo, os agricultoresdoSul que vivem aqui trabalham na lavoura até o meio-dia, ai vão almoçar, depois fazem a sesta até às duas horas e depois voltam para casa e só dormem às dez horas. Os nordestinos começam a trabalhar na mesma hora, mas continuam trabalhando na hora do almoço e lá para as três horas deixam a roça e às oito horas já vão dormir. Entâo veja como é dificil juntaros pensamentos..."

Os nordestinos, como expressa o $\mathrm{Sr}$. Luís Carlos Silvla, também reconhecem as diferenças culturais existentes entre eles e os sulistas: "...é verdade que nós num têm os mesmos modos deles e isso é dificultoso para a gente trabalhar e viver juntos..."

Nas narrativas apresentadas aparecem elementos que, inter-relacionados constituem a base mais geral da identidade do trabalhador rural de Indaiá: a propriedade da terra, uma concepção específica do trabalho e a etnicidade.

A oposição entre nordestinos e sulistas em Indaiá, é marcada, através do discurso dos segundos, por uma concepção de trabalho etnicamente fundamentada. Em primeiro lugar, não concebem o nordestino como bom lavrador, e consideram o "trabalho familiar" no assentamento como exclusivo dos descendentes de imigrantes, ou seja, os sulistas. Não se trata apenas de julgar o nordestino ineficiente, atrasado, improdutivo, preguiçoso e indivíduo que não sabe cuidar da terra e outros tantos estereótipos de uso corrente na região. Nem de acentuar exclusivamente 0 pioneirismo dos primeiros gaúchos na parte meridional do Mato Grosso do Sul, existente desde a "Nova Querência" quando estes, nos trilhos da erva-mate, seguiram em magote para as terras sul-matogrossenses. Ou seja, o discurso do pioneirismo, ou daqueles que primeiro ocuparam o sul do Mato Grosso do Sul é, muitas vezes, utilizado para justificar a desqualificação dos nordestinos no assentamento.

Nas representações imaginárias dos sulistas, eles se afirmam, no assentamento, como descendentes de imigrantes que trouxeram o progresso a uma região inculta, enquanto os nordestinoschegaram muito depois, para usufruir os benefícios do trabalho alheio. No imaginário dos nordestinos, eles percebem uma diferença cultural existente nos dois grupos, expressas na forma de plantar, colher, no horário de ir à roça. Não se apreendem como inferiores 
para o trabalho na lavoura e acreditam que a tradição do trabalho da lavoura é perpassada para eles com eficiência pelos grupos de origem nacional. Nesse sentido, na percepção desse grupo a etnia não é levada em conta na elaboração de suas identidades.

Contudo, se o pioneirismo pode ser pensado em termos de quem primeiro ocupou a região, também está relacionado à questão do trabalho e ao povoamento através do assentamento em linhas coloniais. Nesse sentido, os demais imigrantes, que receberam lotes nas inúmeras picadas abertas na floresta, também foram pioneiros, lutaram contra as adversidades, acreditaram em melhores dias e exerceram um processo de trabalho do qual participaram todos os membros da família.

A participação da mulher e dos filhos no processo de produção agrícola - "o trabalho de todos" - é considerado peculiar aos sulistas e inexistente entre os nordestinos. Imagem desfocada, entre os nordestinos só os homens trabalham, e muito menos do que deviam! Nas representações imaginárias dos sulistas a mulher nordestina " não trabalha na roça"'. O não trabalhar, aqui, significa não participar das atividades produtivas. E os estereótipos aparecem com mais força quando o assunto é casamento. A condenação aos casamentos com nordestinas se faz a partir de imagens como a preguiça feminina, como bem expressou a voz de um lavrador sulista:

"...Lá quando a gente casa ganha tudo. Isso é o costume, a moça traz o dote. E se o camarada casa com uma nordestina, tem de comprar tudo... Já o nordestino é aquela coisa, as mulheres não trabalham, fica tudo por conta do homem, que já não é grande coisa...". $\mathrm{E}$ os nordestinos afirmam:

"...entre os sulistas também tem mulher preguiçosa, são aquelas das pernas grossas as que menos trabalham e a mulher nordestina nãoleva mesmonada procasamento, levarpra que?", narrou José Luís.

Narrativas como essas explicitam as diferenças culturais, especialmente aquelas relacionadas à família e à herança. $\mathrm{O}$ casamento entre grupos étnicos diferenciados revela-se como ameaça à própria reprodução social, diante das diferenças de costumes e de estilo de vida, utilizadas como limites entre os dois grupos.

No caso das identidades étnicas especí- ficas, a origem dos lavradores é apreendida como valor simbólico, um dos critérios definidores da comunidade étnica. Ter origem comum, não brasileira, é um traço que os aproxima e fortalece as diferenças entre os nordestinos. A origem então se destaca como expressão máxima da identidade do lavrador de Indaiá; o segundo especifica a origem ćtnica nacional e, nesse caso, são reconhecidas diferenças dentro do próprio segmento dos colonos. A distinção mais importante, no entanto, é aquela estabelecida entre assentados em geral e os nordestinos - estes considerados como indivíduos desenraizados, sem origem "nobre". Assim, a vocação para o trabalho com a terra é apreendida como relacionada à origem étnica do lavrador, concebida geneticamente. Nessa percepção, o nordestino, de origem nacional também não tem apego ao trabalho e à terra. Vejamos como se expressou o senhor Valdi sobre essa questão, demonstrando o que também pensavam muitos outros lavradores:

"...É, o nordestino trabalha menos do que nós. Parece que ele não tem apegoà terra e não gosta de ficar só mum lugar, ele parece que nem dá valor à terra que possui..."

Essa fala de Valdi expressa a forma como ele e muitos outros lavradores concebem a constante migração nordestina e o valor que atribuem à propriedade. Para esses lavradores, a crença subjetiva na "origem'" fornece os limites do assentamento, fundamentado nas semelhanças de costumes, modos de vida, luta pela terra, etc., atribuídos aos lavradores de Indaiá em geral. Tal crença é reforçada por questões que dizem respeito à terra: consideram que o sulista tem apego à terra e, por ser um lavrador descendente de europeus, dá valor à propriedade, não tem o instinto nômade do nordestino: "o nordestino não tem raiz, não trabalha, está hoje aqui, outro dia lá", relatou Luís Carlos.

Esse relato de Luís Carlos mostra como o passado pioneiro dos imigrantes europeus é ainda utilizado como parâmetro para a construção de uma identidade idealizada, de um conceito de lavrador que leva em conta, sobretudo, o caráter étnico. Parte do pressuposto de que a dedicação e o amor ao trabalho, a eficiência, a habilidade, enfim, todos aqueles traços que os tornam diferentes e melhores que os nordestinos decorrem da sua condição de descendentes de povos europeus. Ea distinção entre os dois grupos, segundo expressaram vários lavradores é visível no confronto da aparência das casas, das terras, das plantações e na existência de hortas e jardins! Os nordestinos, dizem os sulistas, fazem no máximo uma roça. Já os nordestinos se reconhecem realmente diferentes dos sulistas e o Sr. Bruno rememorou:

"...A gente não tem sangue nas veias de outros povos, mas isso não quer dizer que nós também não seja muito trabalhador e se nós muda nuito de lugar é porque gosta muito da terra e não quer ser vagabundo..."

Na narrativa de Bruno, observa-se que o caráter étnico se dilui na construção do conceito de lavrador. Para ele, como para muitos outros, a categoria lavrador se confunde com ser trabalhador e mostra que a vida nômade que levam não diz respeito apenas aos seus "desejos", mas às condições estruturais do país em que vivem e que se expressam na grande concentração fundiária, na necessidade de manterem suas identidades como trabalhadores rurais, preservação de suas memórias e outros.

Mas, apesar de reconhecerem as diferenças, esses lavradores percebem que existe entre eles um passado comum de luta pela terra e a mesma condição de estarem "em cima da terra", lutando para nela se fixarem. É como se eles fossem bordando as suas vidas com matizes diferentes mas sob um risco que lhes é comum - o passado, pleno de gosto pela terra, da luta árdua para conquistá-la e torná-la produtiva e, sobretudo, do desejo de se manterem como homens da roça e, desse modo, preservarem suas memórias, tradições e cultura de trabalhadores rurais. E, é nesta relação estabelecida entre essas diversidades e semelhanças que vão identificando uma identidade coletiva. (Muszkat: 1986)

* Cléria B. da Costa é Dra., Profa. em História Social-UnB.

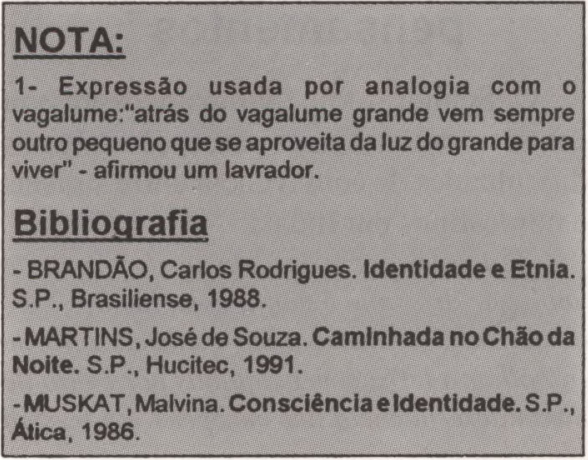

